\title{
FORMAÇÃO DE PROFESSORES DE EDUCAÇÃO FÍSICA: DIRETRIZES PARA A FORMAÇÃO UNIFICADA.
}

Celi Zulke Taffarel*

\begin{abstract}
RESUMO
O texto trata da formação de professores de Educação Física. Critica as atuais diretrizes curriculares, a divisão na formação e a atuação do Sistema Conselho Federal de Educação Física/Conselhos Regionais de Educação Física (CONFEF/CREF). Explica as raízes históricas que determinam esta situação, reconhecendo tendências. Apresenta um arrazoado científico que sustenta a proposição de diretrizes curriculares para um curso de licenciatura plena, de caráter ampliado, em contraponto às atuais diretrizes propostas pelo Conselho Nacional de Educação (CNE) e pelo Sistema CONFEF/CREF.
\end{abstract}

Palavras-Chave: Formação de professores de Educação Física. Diretrizes curriculares.

\section{INTRODUÇÃO}

A Universidade Federal de Santa Maria (UFSM) iniciou a primeira turma do Curso de Educação Físicas em 1970 (MAZO, 1997). Após várias reestruturações curriculares e da divisão na formação entre Licenciatura e Bacharelado, no decurso de mais de 40 anos, impõe-se o debate sobre a formação unificada e, levanta-se a necessidade da critica as atuais diretrizes e referenciais para novas diretrizes curriculares visando superar a divisão na formação acadêmica. Para criticar as diretrizes atuais para a formação de professores em geral e, em especial de formação de professores de Educação Física, partimos de quatro pressupostos. O primeiro diz respeito ao sentido da crítica ao modo de produção capitalista que está levando a humanidade à degeneração, destruição (A VERDADE 2009). O segundo diz respeito ao marco regulatório previsto na Constituição da República Federativa do Brasilenquanto marco referencial da lei maior que rege as relações no modo de produção capitalista, de acordo com seu grau de desenvolvimento, neste momento histórico. O terceiro diz respeito ao projeto histórico para orientar o debate acadêmico, a formulação das pesquisas e a formação e atuação de professores, particularmente dos professores de Educação Física. O quarto diz respeito à realidade atual dentro da qual está inserida a disputa de projetos de 
formação do professor de Educação Física. De um lado a tendência conservadora de formação dividida em dois cursos e, de outro, a proposta revolucionária de formação unificada, em um curso de graduação - licenciatura plena de caráter ampliado. Para contribuir com o debate colocado na própria UFSM que está reestruturando seu currículo de graduação em educação física, reabrindo seu programa de pós-graduação em Educação Física e, reeditando seu periódico (Revista Kinesis) é que apresentamos a proposta a seguir descrita de diretrizes para a formação unificada, Licenciatura Plena em Educação Física, de caráter ampliado.

\section{AS REFORMULAÇÕES CURRICULARES DA EDUCAÇÃO FÍSICA BRASILEIRA}

No marco do modo de produção capitalista no Brasil, as Reformulações Curriculares da Educação Física podem ser localizadas nos seguintes marcos temporais, com as respectivas normatizações, modalidades e perspectivas de duração do Curso:

\begin{tabular}{|c|c|c|c|}
\hline Ano & Decreto/ Resolução & Modalidade & $\begin{array}{c}\text { Duração do } \\
\text { curso }\end{array}$ \\
\hline 1939 & Decreto-Lei 1212/39 & Licenciatura em Educação Física & 02 anos \\
\hline 1945 & Decreto-Lei 8270/45 & Licenciatura em Educação Física & 03 anos \\
\hline 1969 & $\begin{array}{c}\text { Resolução CFE } \\
69 / 1969\end{array}$ & Licenciatura em EF e Técnico Desportivo & 03 anos \\
\hline 1987 & $\begin{array}{c}\text { Resolução CFE } \\
03 / 1987\end{array}$ & Licenciatura e/ou Bacharelado em EF & 04 anos \\
\hline 2004 & $\begin{array}{c}\text { Resolução CNE } \\
07 / 2004\end{array}$ & Graduado em Educação Física & 04 anos \\
\hline
\end{tabular}

Fonte: Cruz (2009). 
A estes marcos temporais correspondem determinados graus de desenvolvimento das forças produtivas, graus de desenvolvimento da luta de classes, graus de desenvolvimento da correlação de forças entre trabalho e capital.

As leis são determinadas pela base material da produção da vida e decorrem da luta travada na superestrutura da sociedade para manutenção/superação do modo de produção.

A legislação mais atual que incide na formação de professores é de 2001 e 2002 e a referente à graduação em Educação Física é de 2004 (Parecer CNE/CES 058/2004 e Resolução CNE/CES 07/2004). Esta legislação demarcou o campo de atuação do Graduado em Educação Física, ou seja, quem tem a titulação de Graduação em Bacharelado ou Tecnólogo de Educação Física ${ }^{1}$, só pode atuar em áreas não escolares. Entretanto, aquele que possui a Graduação - Licenciatura Plena, pode atuar na área escolar e nas outras áreas que a titulação Graduação, segundo a referida resolução, permite atuar.

O CONFEF foi instituído pela Lei 9.696 de 01 de Setembro de 1998 e em seu estatuto, Artigo $1^{\circ}$, Inciso $2^{\circ}, 0$ Sistema tem o: "poder delegado pela União para normatizar, orientar, disciplinar e fiscalizar o exercício das atividades próprias dos Profissionais de Educação Física e das pessoas jurídicas, cuja finalidade básica seja a prestação de serviços nas áreas das atividades físicas, desportivas e similares" (CONFEF, 2010a).

Vejamos as características, em linhas gerais, de cada período histórico que correspondeu a alterações na legislação, a saber, nas décadas de 1930, 1940, 1960, 1980 e anos 2000 e, os argumentos científicos para diretrizes curriculares que unifiquem a formação.

A década de 1930 tem por característica básica a depressão econômica, com a quebra da bolsa de valores em 1929, a ascensão do nazismo, fascismo,

\footnotetext{
${ }^{1}$ Tecnólogo em Educação Física é uma modalidade de formação que está em discussão no país e encontra, por exemplo, na formação em nível de Ensino Médio, algumas experiências já em desenvolvimento. Verificar em: <http://www.educacaofisica.com.br/index.php/gestao/128-cursos-eeventos/21806-curso-tecnico-esportes-atividade-fisica-profissionais-de-educacao-fisica>. Acesso em: 25 mai. 2012.
} 
stalinismo. No Brasil, a Revolução de Trinta instala no poder Getúlio Vargas inicia o Estado Novo (1937-1945). Com ele, a política desenvolvimentista que exigia uma política correspondente no campo da formação de professores para o enquadramento da classe trabalhadora em tal perspectiva ideológica. Mas isto tudo dentro de uma feroz e disputadíssima luta entre as classes, principalmente o operariado e os proprietários dos meios de produção. Vargas orientou a intervenção estatal na economia e a nacionalização e fortaleceua industrialização. Decretou o Código Penal e o Código de Processo Penal e a Consolidação das Leis do Trabalho (CLT), todos até hoje em vigor. Além disso, criou a carteira de trabalho, a Justiça do Trabalho, o salário mínimo, a estabilidade do emprego depois de dez anos de serviço (revogada em 1965), substituída pelo Fundo de Garantia por Tempo de Serviço (FGTS), e o descanso semanal remunerado.

A década de 1940 é reconhecida como o apogeu de conflitos mundiais sangrentos, deflagração de bombas atômicas e tensões entre União Soviética e Estados Unidos com a chamada Guerra Fria; é a década de criação da Organização das Nações Unidas (ONU), Organização do Tratado do Atlântico Norte (OTAN), Fundo Monetário Internacional (FMI) e Banco Mundial e de início do Plano Marshall de recuperação econômica da Europa.

A década de 1960 representou uma virada à esquerda, reconhecida, por exemplo, na consolidação da Revolução Cubana e avanços dos partidos de trabalhadores no mundo, o que levou a intervenções militares sangrentas na América Latina para conter esta tendência. O Brasil não esteve incólume a isto e instalou-se aqui o Regime Militar. Tratou-se também de um período de sangrentas lutas pela independência principalmente dos países africanos.

A década de 1980 caracteriza-se por mais de 70 conflitos armados no mundo. Nesta década ocorre o Consenso de Washington, reunião de organismos internacionais que listaram políticas orientadas pelo Banco Mundial e pelo FMI a serem empregadas pelos países imperialistas. Entre as medidas constavam: entregar a economia às leis do mercado; intervenção estatal somente para garantir lucros dos capitalistas; abertura das economias pela liberalização financeira e comercial e liberação de barreiras impeditivas as lucros do capital internacional; ampla privatização; redução de subsídios e gastos sociais por parte de governos; desregulamentação do trabalho para 
permitir novas formas de contratação que reduzam custos aos empresários e ampliem exploração da mais-valia, dos lucros resultantes da exploração da força de trabalho.No Brasil, é o período em que ocorre o ascenso na organização da classe trabalhadora, em que nasce o Movimento dos Trabalhadores Sem Terra (MST), a Central Única dos Trabalhadores (CUT), o Partido dos Trabalhadores (PT). É retomada a União Nacional dos Estudantes (UNE). Os organismos internacionais avaliam, fazem balanço e estabelecem a política planetária para manter a hegemonia do capital. O Consenso de Washington é um exemplo destes ajustes requeridos pelo capital. Iniciando os anos 90, o Brasil instala a Reforma do Estado capitaneada por Bresser Pereira, visando os ajustes a tais políticas.

Entramos nos anos 2000 com a tendência à cooptação da classe trabalhadora e destruição dos seus organismos de luta para que os ajustes estruturais, os planos de austeridade, fossem aplicados e aprofundados. Entramos nos anos 2000, mais uma vez, com o capital em franca agonia arrastando a classe trabalhadora à destruição. Isto é evidente nos ajustes estruturais e na austeridade cada vez mais aprofundada para manter a hegemonia do sistema. Países vão à bancarrota e levam consigo direitos e conquistas da classe.

Portanto, a recomposição do aparato legal corresponde às tendências econômicas, entre as quais podemos reconhecer a de desregulamentar o mundo do trabalho, controlando, ajustando, enquadrandoa força de trabalho por outros mecanismos entre os quais a regulamentação das profissões, a divisão na formação acadêmica, a criação de conselhos e a desregulamentação do trabalho, a flexibilização, a terceirização, a privatização, a transferência de recursos públicos ao setor privado. Exemplos não nos faltam no Brasil. Desde os cortes no Orçamento Geral da União, as privatizações, a substituição dos serviços públicos pelos serviços terceirizados ou, simplesmente, repasses para organizações não governamentais de tais responsabilidades, as políticas compensatórias, focais, dos "mínimos" rebaixando a formação da classe trabalhadora para ampliar lucros do capital.

Estes mecanismos incidem sobre a classe trabalhadora, para desqualificá-la no processo de formação e, assim, melhor explorá-la. Um destes mecanismos é a divisão na formação acadêmica, que fragiliza, pelo 
esvaziamento teórico, a formação dos trabalhadores. O outro é na inserção e atuação nos campos de trabalho, delimitando a atuação e, com isto, restringindo a intervenção da classe trabalhadora nos campos de trabalho. $O$ aparato legal daí decorrente é resultante, portanto, da economia política e das leis gerais que regem o capitalismo.

\section{PERIODO DE TRANSIÇÃO - AS RESISTENCIAS A FORMAÇÃO DIVIDIDA}

Estamos em um período histórico de transição para outro modo de produção, visto que o capitalismo está levando a humanidade à destruição ( $A$ VAERDADE ; 2009). Isto exige refletirmos sobre a formação de professores tendo em vista um modo de produção a ser superado e outro em construção. É neste contexto histórico de transição que estamos tratando das diretrizes da formação de professores de educação física.

Dados levantados junto ao Ministério da Educação demonstram que existem atualmente duas modalidades de formação da Educação Física: a Licenciatura e a Graduação (Bacharelado) em um total de 1.103 cursos de formação distribuída da seguinte maneira: 663 licenciaturas e 440 bacharelados. Destas, somente 137 são licenciaturas em Universidades Públicas Presenciais. Fonte:Ministério da Educação - Sistema e-MEC. Disponível em: <http://emec.mec.gov.br/>. Acesso em: 05 abr. 2012.

A maioria das Licenciaturas e Bacharelados estão nas Universidade/Faculdades Privadas. Surgem, também, neste momento histórico, as iniciativas de formação à distância, inclusive incentivadas pelo governo através da Universidade Aberta do Brasil (UAB), que proporciona a Educação à Distância (EAD). O governo prevê a formação de um milhão de docentes para a Educação Básica à distância².

Evidenciam-se, nestes dados, portanto, três tendências na formação de professores de Educação Física brasileira: os cursos de bacharelado que visam formar profissionais para atuarem no mercado não escolar, a iniciativa

\footnotetext{
${ }^{2}$ Este propósito poderá ser encontrado no pronunciamento do Secretario de Educação à Distância do MEC, Ronaldo Mora. Disponível em: <http://www.abraead.com.br/artigos ronaldo.html>. Acesso em: 25 mai. 2012.
} 
privada na formação, que visa lucros com a formação de profissionais e a iniciativa à distância, que visa o aligeiramento e diminuição nos gastos com a formação de professores.

Os estudos de Nozaki (2004), Alves (2005), Santos Júnior (2005), Lemos (2008), Brito Neto (2009), Cruz (2009), Coimbra (2010), Dias (2011), Aranha (2011), Dutra (2011), Silva e Frizzo (2011), Morschbacher (2012) que tratam da formação de professores, da produção do conhecimento e da atuação profissional, descrevem, com muita propriedade, nexos e relações entre a economia política e as tendências conservadoras na formação e atuação profissional de professores de Educação Física.

As tendências contrarrevolucionárias, tendências de amoldamento da classe, tendências ao assalto da subjetividade humana, tendência à desqualificação do trabalhador em seus processos de formação acadêmica, estão fortemente alicerçadas em aparatos legais, em táticas e mediações de aparelhos do estado, como é o Conselho Federal de Educação Física (CONFEF) e de associações entre organismos da classe capitalista, como bem demonstra Coimbra (2010) em seus estudos sobre a reorganização empresarial do âmbito do Fitness, entre CONFEF/CREF, Associação das Academias do Brasil (ACAD) e o Sindicato dos proprietários das Academias de Ginástica (SINDICAD).

Coube, conforme demonstram os estudos de Dutra (2011) - que recorreu aos exemplares da Revista de Educação Física do (CONFEF) ${ }^{3}$ - a esse órgão de fiscalização da profissão, posicionar-se em relação as atuais diretrizes curriculares. Dutra (2011) analisou as posições do Sistema CONFEF/CREF através de suas publicações e concluiu que os principais argumentos enfatizam a divisão entre olicenciado que só pode atuar na escola e o bacharel, só pode atuar nos demais campos da Educação Física. O Conselho afirma que o termo Graduação corresponde ao Bacharelado:

A LICENCIATURA: a formação de professores que atuarão nas diferentes etapas e modalidades da educação básica, portanto, para atuação específica e especializada com a componente curricular

\footnotetext{
${ }^{3}$ Ver em:CONFEF. Estatuto do Conselho Federal de Educação Física. Rio de Janeiro, nov. 2010. Disponível em: <http://www.confef.org.br/extra/conteudo/default.asp?id=471>. Acesso em: 25 set. 2011.
} 
Educação Física. O BACHARELADO (oficialmente designado de graduação) qualificado para analisar criticamente a realidade social, para nela intervir por meio das diferentes manifestações da atividade física e esportiva, tendo por finalidade aumentar as possibilidades de adoção de um estilo de vida fisicamente ativo e saudável, estando impedido de atuar na educação básica (CONFEF, 2006, p. 20).

O Conselho expressa a necessidade da ingerência na formação,tendo em vista os rumos da formação e os mercados de trabalho, dada a demanda de uma reestruturação produtiva do capital:

[...] identificam-se diferentes expectativas que refletem, entre outros aspectos, a dinâmica das mudanças educacionais em curso no País, as inovações específicas no campo da intervenção profissional, decorrentes da regulamentação da profissão de Educação Física e até mesmo as incertezas dos jovens acadêmicos diante do futuro profissional e da crise de empregabilidade que caracterizam este novo século. Não há como negar que os novos desafios impostos à formação em Educação Física são diferentes daqueles enfrentados há dez anos. As grandes questões e as principais dúvidas podem até ser as mesmas, mas os contextos são diferentes e exigem novos argumentos, novas abordagens e novas estratégias para superá-los. (CONFEF, 2009, p.28).

As posições do Conselho, que em suas legislações específicas delimitam campos de atuação do profissional - professor de Educação Física, vêm gerando lacunas na formação, lacunas que são sentidas durante o processo de formação, bem como na atuação profissional, nos campos de trabalho.

As lacunas na formação dizem respeito à negação do conhecimento $\mathrm{e}$ as lacunas na atuação profissional dizem respeito à negação de postos de trabalho. A expressão desta negação pode ser identificada nas atuais reivindicações do Movimento Estudantil da área, que reivindica a revogação das diretrizes curriculares e a reformulação dos currículos na perspectiva da unificação.

O Sistema CONFEF/CREF com suas argumentações ideológicas e com seu aparato legal atua para restringir, portanto, a formação e atuação profissional, interferindo na universidade e nos campos de trabalho - e isto é 
observável na "realidade atual" em que se aliam outros fatores que desqualificam o professor em sua formação acadêmica.

$\mathrm{Na}$ busca de elementos de resistência a tal ingerência localizamos seis fontes de dados, a saber:

1) A atuação do Movimento Nacional Contra a Regulamentação da Profissão (MNCR), que há 12 anos vem formulando e enfrentando o aparato do CONFEF/CREF tanto no plano jurídico ${ }^{4}$, quanto nas lutas cotidianas. Ademais, produziu dois livros que sintetizam as posições do Movimento e suas batalhas. São eles: DIAS JÚNIOR, Elson Moura; LIMA, Thiago Firminio de. MNCR: 10 anos de luta pela regulamentação do trabalho. Feira de Santana/BA: UEFS Editora, 2010; ALMEIDA, R. (Org.). Os bastidores da regulamentação do profissional de educação física. Vitória: CEFD/UFES, $2002^{5}$.

2) A Executiva Nacional dos Estudantes de Educação Física (ExNEEF) que, no Manifesto “Educação Física é uma só! Formação Unificada Já”, Gestão 2010/2011, apresenta 10 "motivos para sermos a favor da Licenciatura Ampliada". Entre estes motivos constam:Formação ampla para atuação nos demais âmbitos dos campos de trabalho; Sólida base científica; Cultura Corporal como objeto de estudo; Unidade entre teoria e prática; Indissociabilidade entre ensino, pesquisa, extensão; Articulação de conhecimentos; Avaliação; Formação continuada; Prática pedagógica como caracterização da área; Projeto alternativo de universidade - outra concepção de formação, de homem, de mundo e de universidade.

3) Periódicos científicos como a revista Motrivivência que em seus exemplares denominados Educação Física e o Mundo do Trabalho I (Ano XXII, n. 35, jun. 2010) e Educação Física e o Mundo do Trabalho II (Ano XXIII, n. 36, jun. 2011), tratam da temática da Educação Física e o Mundo do Trabalho apresentando argumentos científicos que demonstram os interesses de classe em conflito e confronto na área.

\footnotetext{
${ }^{4}$ Ver mais sobre a luta no jurídico na audiência pública ocorrida em Feira de Santana/Bahia no dia 10 de maio de 2012 (Disponível em: <http://mncref.blogspot.com.br/>). Segundo o Ministério Público Federal:"a audiência cumpriu sua dupla finalidade de informar aos profissionais sobre a liminar da Justiça Federal na Bahia, que garante aos licenciados na área trabalhar também em ambientes não escolares, além de fomentar o debate".

${ }^{5}$ Ver mais em: <http://mncref.sites.uol.com.br/tdocs.htm>.
} 
4) Intelectuais orgânicos comprometidos com a classe trabalhadora que deixam evidente em seus estudos científicos dados concretos e objetivos que demonstram as táticas e mediações do capital para desqualificar e explorar os professores de Educação Física. Entre os estudos mencionamos: Taffarel (1993), Nozaki (2004), Alves (2005), Santos Júnior (2005), Lemos (2008), Brito Neto (2009), Cruz (2009), Coimbra, (2010), Silva e Frizzo (2011), Dias (2011), Aranha (2011), Dutra (2011) e Morschbacher (2012).

5) As propostas de unificação que estão sendo levadas em cursos que discutem a reformulação e a possibilidade de Unificação, como são exemplos os debates e as propostas apresentadas pelos estudantes, aliados a intelectuais orgânicos, sempre em minoria, na UFSM, UFRGS, UFG, UFBA, UEPA, UFMS, UNIMAT, entre outros cursos no Brasil.

O MNCR vem travando uma batalha nos campos jurídicos e ideológicos sem precedentes na história da Educação Física, contra a ingerência do Sistema CONFEF/CREF em todas as instituições onde se definem a formação acadêmica, a atuação profissional, a produção do conhecimento e as políticas públicas.

Os intelectuais orgânicos, por sua vez, estão travando a luta por dentro da universidade na defesa do preceito institucional da autonomia universitária. Identificamos que o pressuposto institucional, presente na Constituição da República Federativa do Brasil, ali instituído, após uma longa e histórica luta da classe trabalhadora, que tem seu desfecho na promulgação da Lei Maior do Brasil, em 05 de outubro de 1988, prevê em seu Artigo 207 a autonomia universitária:

Art. 207. As universidades gozam de autonomia didático-científica, administrativa e de gestão financeira e patrimonial, e obedecerão ao princípio de indissociabilidade entre ensino, pesquisa e extensão (BRASIL, 2009).

É garantido, portanto, que a universidade exerça as suas funções precípuas, a saber, ensino, pesquisa e extensão, respaldada na Constituição Nacional para propor o que for de mais avançado, bem como nos rumos do projeto político pedagógico de formação dos profissionais em geral e, em 
especial, dos professores de Educação Física. É garantido, portanto, aos que frequentam a universidade e integralizam o currículo o exercício da profissão a qual foram formados.

No entanto, independente deste aparato legal maior, os estudos demonstram a total perda de autonomia da universidade, corroborando tese que defendemos em 1993 sobre a necessidade do capital de desqualificar o trabalhador em seu processo de formação para extrair mais-valia e, com isto, manter ou recompor taxas de lucro explorando a força de trabalho.

Os estudos sobre formação do profissional, professor de Educação Física (TAFFAREL, 1993) demonstram a necessidade vital da referência ao projeto histórico para orientar o projeto político pedagógico de uma universidade, orientar a formação de professores - em especial, os profissionais da Educação Física. Conforme Freitas (1995, p.142):

Um projeto histórico aponta para a especificação de um determinado tipo de sociedade que se quer construir, evidencia formas para chegar a esse tipo de sociedade e, ao mesmo tempo, faz uma análise crítica do momento histórico presente. Os partidos políticos (embrionários ou não) são os articuladores dos projetos históricos. A explicitação de como articulamos essas três instâncias parece ser essencial à própria pesquisa pedagógica. A necessidade de um projeto histórico claro não é um capricho. É que os projetos históricos afetam nossa prática política e de pesquisa, afetam a geração dos próprios problemas a serem pesquisados.

O Projeto Histórico ${ }^{6}$ é o eixo em torno do qual devem se definir as orientações pedagógicas, assegurando dessa forma que o "estatuto progressista" do discurso seja menos uma qualificação ideológica do que objetivamente revolucionário. Tratamos aqui da formação humana e da formação de professores de Educação Física na perspectiva do projeto

\footnotetext{
${ }^{6}$ Segundo Freitas (1987) em seu texto Projeto Histórico, Ciência Pedagógica e "Didática" (FREITAS, Luiz Carlos. Projeto histórico, ciência pedagógica e "didática". Educação \& Sociedade, São Paulo, ano IX, v. 09, n. 27, p.122-140, set. 1987), a discussão em torno do Projeto Histórico ou, mais apropriadamente, dos projetos históricos subjacentes às posições progressistas na área educacional é necessária para entendermos melhor a aparente (e só aparente) identidade do discurso "transformador" nesta área: um Projeto Histórico enuncia o tipo de sociedade ou organização social na qual pretendemos transformar a atual sociedade e os meios que devemos colocar em prática para a sua consecução. Implica uma "cosmovisão", mas é mais que isso. É concreto, está amarrado às condições existentes e, a partir delas, postula fins e meios. Diferentes análises das condições presentes, diferentes fins e meios geram projetos históricos diversos. Tais projetos fornecem base para a organização dos partidos políticos.
} 
histórico comunista, superador das exauridas e destrutivas relações capitalistas que estão levando a humanidade à barbárie.

Outro elemento vital a considerar na formação profissional do professor de Educação Física é a realidade atual de degeneração e decomposição do modo de produção capitalista. Assim sendo, entender a realidade como direcionamento da formação de professores de Educação Física é colocar as problemáticas no contexto dos conflitos sociais que acirram a luta de classes determinando para a classe trabalhadora a perda do direito ao trabalho, à terra, à saúde, o recrudescimento do analfabetismo e da violência, a mortalidade por doenças decorrentes da destruição do meio ambiente e outros. A realidade atual implica perspectivar o ensino e a pesquisa em relação ao "contemporâneo", que não é, infelizmente, o progresso científico e tecnológico chegando a todos, senão as consequências trágicas das novas formas de exploração e de aculturação nos países menos desenvolvidos ou periféricos. Esse "contemporâneo", apregoado pela direita, cobriu com doces ilusões a miséria para se colocar como real. Enfim, a "realidade atual" caracteriza-se pelos determinantes sociais da educação, ciência, tecnologia confrontando o dia-a-dia da prática pedagógica na formação de professores de Educação Física.

A "realidade atual" na formação de professores nos permite levantar a hipótese de que está em curso um processo de desqualificação e destruição das forças produtivas, das quais consta 0 trabalho e 0 trabalhador, que se expressa na formação dos trabalhadores, nos seus processos de qualificação acadêmica e de atuação profissional. Processos que, contraditoriamente, se dão pela negação do conhecimento científico, pelo estabelecimento de consensos, pela coerção, pela regulamentação e pela criação de conselhos de caráter privatista. Processos que se consolidam pelas seguintes táticas do capital:

10 Retirada dos intelectuais orgânicos da luta de classes e sua transformação em intelectuais institucionais (PETRAS, 1996), inseridos na implementação das políticas mundiais de educação e na consolidação da nova pedagogia hegemônica do capital para educar o consenso (NEVES, 1997; 2002; 2005); 
2o Recuo da teoria, (MORAES, 2003), que desconsidera leis mais gerais que regem o modo de produção da vida, o Estado burguês e a sua organização hegemônica e que desconsidera a luta de classes. Prevalecem, hegemonicamente, teorias idealistas, pós-modernas, que eliminam o real e defendem o relativismo epistemológico, o escolanovismo e o neotecnicismo como as teorias pedagógicas mais avançadas (DUARTE, 1998; 2003).

3 Diretrizes curriculares fragmentadas e que rebaixam a formação omnilateral, privilegiando a divisão social do trabalho na formação acadêmica;

4- Currículos de graduação rebaixados teoricamente, pelo esvaziamento de conteúdos científicos, pelo relativismo epistemológico. Currículos com ênfase na práxis do cotidiano, esvaziados de formação política, de elementos sobre auto-organização, autodeterminação, organização revolucionária, práxis revolucionária; currículos esvaziados de coerência e consistência entre premissas teóricas e programáticas.

50 Regulamentação do profissional, segundo a legislação vigente, com base em mercados de trabalho que se expandem e se contraem de acordo com os lucros do capital, em detrimento do fortalecimento do sistema de proteção do trabalho;

6- Criação de Conselhos de Fiscalização do Profissional, segundo o que prevê a Lei n. 9.649/98 que, em seu artigo 58, prevê que a fiscalização de profissão regulamentada será exercida em caráter privado. Além disso, a estrutura e o funcionamento dos conselhos de caráter privado serão exercidos mediante decisão do plenário do conselho federal.

Estas táticas demonstram que a formação dos professores necessita orientar-se no conhecimento aprofundado da luta ideológica, contemporânea, que se manifesta nas características que o capitalismo imprime às tarefas sociais da educação e do esporte. Conhecimento que permite enfrentar e combater o neopositivismo, existencialismo, pragmatismo, entre outras correntes que alimentam o neotecnicismo, as quais isolam a escola e os esportes dos problemas que afetam a sociedade $\mathrm{e}$ incrementam a contraposição dos interesses individuais aos sociais. 


\section{ARRAZOADO CIENTIFICO PARA OUTRAS DIRETRIZES CURRICULARES}

Com essa base delimitada, apresentamos a seguir o arrazoado científico baseado na revisão da bibliografia atualizada e na análise da conjuntura atual que sustenta a proposição de diretrizes curriculares e de trato com conteúdos do currículo - prática do ensino e estágio curricular obrigatório, ambos da Educação Física -, para formar professores de Educação Física, cujo objeto de estudo é a cultura corporal.

Diretrizes para um curso único na perspectiva da formação omnilateral (MANACORDA, 1987), tendo como referência o projeto histórico superador ao atual modo de produção capitalista. Trato com o conhecimento no currículo, em especial a prática do ensino e o estágio supervisionado obrigatório, através de ciclos e sistemas de complexos (PISTRAK, 2000; 2009), materializando-se a tese da articulação do conhecimento no currículo; tendo como eixo articulador do conhecimento o trabalho, em especial o trabalho na sua dimensão ontológica que se expressa na atuação docente como o trabalho pedagógico, com base na cultura corporal.

A proposta de Diretrizes Curriculares que apresentamos a seguir se opõem à fragmentação e divisão dos cursos de formação de professores de Educação Física em Bacharelado e Licenciatura conforme explica o Sistema CONFEF/CREF em seus periódicos. A argumentação aqui presente resulta dos debates e iniciativas adotadas na Faculdade de Educação da Universidade Federal da Bahia (FACED/UFBA) para alterar o currículo de formação de professores de Educação Física.

Estudos como os de Dias (2011), Dutra (2011) e Cruz (2009) demonstram que os embates de projetos diferenciados, antagônicos estão em curso. Este embate se expressa tanto nos rumos da produção científica, quanto nos rumos dos estudos dos Grupos de Pesquisa, na posição assumida no embate teórico, nas instituições científicas da área, como, por exemplo, nos eventos do Colégio Brasileiro de Ciências do Esporte (CBCE), quanto nas experiências de reestruturação curricular. Os casos da UFSM, UFRGS, UFBA, UFPA são emblemáticos e demonstram a resultante da correlação de forças que pode fortalecer a tendência conservadora de fragmentação da formação, ou então, a tendência revolucionária de uma consistente formação teórica, em 
um curso unificado que desenvolverá competências globais e habilidades profissionais científicas para o exercício critico da profissão na perspectiva da emancipação humana.

Os principais problemas identificados nos currículos que estamos estudando são os seguintes: Excessiva carga horária, dispersa e diluída em conteúdos fragmentados; ênfase no currículo biologicista, enfocado na área médica - com ênfase na perspectiva de saúde de matriz patogenética, ou seja, das doenças; currículo desportivizado; currículo com caráter terminal - estágio e práticas do ensino previstos no final do curso; currículo sem Trabalho de Conclusão de Curso (TCC) de caráter científico; currículo sem eixos, pilares, módulos ou sistemas de complexos orientadores no trato com o conhecimento; currículo sem previsão da auto-organização dos estudantes na organização livre dos seus conteúdos curriculares; sem unificação teórico-metodológica em torno de capacidade gerais para o exercício da profissão; currículo sem inserção nas redes públicas - de educação, de saúde, de esporte, de lazer, de treino de alto rendimento; currículo sem delimitação de competências globais, ou seja, do desenvolvimento teórico dos estudantes, com elevação das funções psicológicas superiores; sem delimitação de habilidades daí decorrentes para o exercício da profissão do professor de Educação Física; currículo disperso epistemologicamente em um relativismo científico prejudicial à formação acadêmica; currículo sem delimitação de um objeto preciso de estudo; currículo baseado na teoria pedagógica escolanovista.

Com os avanços das posições críticas na reformulação curricular, reconhecemos as seguintes propostas superadoras: tempo pedagógico redimensionado, enxuto, redefinido no que diz respeito à relação universidadecampos de trabalho; Conteúdos reordenados tendo o trabalho como princípio educativo; conhecimentos organizados em quatro eixos ou módulos: os fundamentos, os conteúdos específicos, a práxis e a formação científica; ênfase no currículo multidisciplinar; objeto de estudo, a cultura corporal; prática do ensino (400 horas) tendo como objeto a aproximação à docência e, o estágio supervisionado (400 horas) de aproximação aos campos de trabalho de acordo com legislação vigente ${ }^{7}$; trabalho de conclusão de curso iniciado no

\footnotetext{
${ }^{7}$ Lei do Estágio - Lei n. 11.788/2008, de 25 de setembro de 2008.
} 
primeiro semestre letivo com o desenvolvimento de atividades educativas orientadoras do trabalho científico (200 horas); currículo com previsão da autodeterminação dos estudantes na organização livre dos seus conteúdos curriculares (200 horas); currículo com inserção nas redes públicas - de educação, de saúde, de esporte, de lazer, de treino de alto rendimento; currículo com delimitação e avaliação sistemática do grau de desenvolvimento da capacidade teórica dos estudantes e das competências globais e habilidades para o exercício do professor de Educação Física que se caracteriza historicamente pela docência, ou seja, o trabalho pedagógico, a atitude científica, a gestão e administração científica, a organização do conhecimento pelo trabalho pedagógico; currículo com uma orientação epistemológica com base na teoria crítica, de referencia marxista; currículo com delimitação de um objeto preciso de estudo - a cultura corporal.

A implementação das diretrizes conforme aqui proposto é uma possibilidade concreta de alteração do currículo de Educação Física na perspectiva do curso único, de graduação plena, de caráter ampliado ${ }^{8}$.

Uma possibilidade concreta é a possibilidade para cuja realização podem ser reunidas, no momento presente, as condições correspondentes. Segundo Cheptulin (1982).

\begin{abstract}
A possibilidade cuja realização não modifica a essência da coisa é denominada de possibilidade de fenômeno; a possibilidade cuja realização está ligada à modificação da essência da coisa, com a sua transformação em uma outra coisa, é denominada de possibilidade de essência (CHEPTULIN, op. cit., p. 344).
\end{abstract}

A compreensão dessa distinção das possibilidades concretas e abstratas, de fenômeno e de essência é de grande importância para a atividade prática e, em particular, para a realização de planificações concretas e em longo prazo. Elas estão em relação direta com a atividade prática humana e sua consideração assegura uma orientação adequada das vias e dos meios de se chegar a esse ou

\footnotetext{
${ }^{8}$ Sobre o curso único, remetemos a Taffarel e Santos Júnior (2010). Reafirmamos aqui nossa posição de que os argumentos científicos, pedagógicos e técnicos que fundamentam a divisão da formação na área da Educação Física são demasiado frágeis. Os defensores do bacharelado continuam, na maioria das vezes, utilizando da referência a um abstrato mercado (que eles nunca cuidam de precisar) e/ou da referência a exigências legais (que o fazem ao arrepio da Constituição Federal do Brasil).
} 
àquele resultado prático. As possibilidades são ilimitadas, à medida que a matéria passa de um estado qualitativo a outro e aparecem novas possibilidades.

A compreensão do subjacente a uma proposição de diretrizes é necessária para a apreensão do lógico e do histórico, dos nexos e das determinações da formação de professores e da escola (SAVIANI, ALMEIDA, SOUZA E VALDEMARIM, 2006; 2006aㅜ), em especial na Educação Física. Neste sentido, buscamos compreender a proposição de diretrizes curriculares nacionais propostas pelo Ministério da Educação (MEC) para os cursos de Licenciatura ${ }^{9}$.

O maior e melhor exemplo do embate entre posições antagônicas está delimitado pelas posições do Movimento Estudantil de Educação Física, única instância de luta que vem defendendo como uma de suas bandeiras e principais reivindicações a derrubada das atuais diretrizes que orientam a formação dos professores de Educação Física no Brasil.

A ExNEEF, a partir de suas deliberações de base, vem orientando 0 Movimento Estudantil da Educação Física (MEEF) a aderirem com consciência de classe elevada à Campanha Nacional "EDUCAÇÃO FÍSICA É UMA SÓ: Formação Unificada Já”. Esta Campanha Nacional reivindica a revogação das atuais Diretrizes Curriculares Nacionais para a formação em Educação Física. O documento da EXNEEF, de 33 páginas e datado de 2010, é uma prova cabal do quanto os estudantes estão avançados em relação à formação do profissional de Educação Física e em relação a outros setores, inclusive que articulam professores de nível superior.

\section{AS BASES CIENTÍFICAS PARA A SUPERAÇÃO}

Reconhecemos ser procedente a posição do Movimento Estudantil de Educação Física, que vem logrando êxito em seus embates na $U_{F R G S^{10}}$ que

\footnotetext{
${ }^{9}$ Na resolução CNE/CES n. 07/2004, de 31 de março de 2004, não existe referência a Bacharelado. A divisão da formação, com base nesta resolução, continua sendo mais uma ingerência do Sistema CONFEF/CREF.
}

\footnotetext{
${ }^{10}$ Na Universidade Federal do Rio Grande do Sul o embate foi instalado, mas o sistema de decisão que prevê o voto proporcional $70 \%$ peso dos votos de docentes, $15 \%$ peso dos votos dos discentes
} 
instalou o debate e, o confronto de idéias e propostas como vem ocorrendo na $U_{F S M}{ }^{11}$. Nas argumentações a seguir expostas estão os elementos que nos permitirão distinguir as propostas do MEC, explicitar antagonismos e apresentar a superação.

É imperiosa a compreensão do caráter multidisciplinar que caracteriza a formação e ação profissional/acadêmica na Educação Física, como também a necessidade da presença nos currículos de conhecimentos clássicos e conhecimentos originários tanto do campo das Ciências Biológicas/Saúde como das Ciências Humanas/Sociais, da Terra, das Ciências Exatas e da Natureza, da Filosofia e das Artes.

$\mathrm{Na}$ perspectiva de superar a concepção fragmentada de ciência, expressa na proposta de divisão dos cursos de formação do professor de Educação Física, propõe como MATRIZ CIENTÍFICA para a formação dos professores o materialismo histórico dialético. É a ontologia e a história: a história do homem e sua relação com a natureza e a relação dos seres humanos entre si produzindo e reproduzindo a vida, construindo a psique humana (WIGOSTKY; 1987; WIGOTSKY, LURIA, e LEONTIEV; 1988). Tal proposta assegura-se quando da colocação da primeira pergunta ontológica para compreensão do ser humano - como o homem torna-se homem e como se dá o conhecimento?

A relação estabelecida pelo ser humano e a natureza, para garantir sua existência, dá-se no curso da história, portanto, somente a partir da história enquanto ciência é possível tanto apreender quanto compreender o passado, o presente e o futuro do ser humano (MANACORDA; 1987). Ao longo da história, também se configura a cultura corporal e 0 trabalho pedagógico, pontos centrais que estabelece identidade ao profissional de Educação Física.

A Educação Física se caracteriza historicamente pelo trabalho pedagógico da docência no campo da cultura corporal, ou seja, a ação pedagógica no trato com o conhecimento da cultura corporal. Em qualquer campo de trabalho, a ação pedagógica é a base da formação acadêmica e do

estudantes e $15 \%$ peso votos dos funcionários técnico-administrativos derrotou a proposta dos estudantes.

\footnotetext{
${ }^{11} \mathrm{Na}$ Universidade Federal de Santa Maria a proposta dos estudantes foi vitoriosa.
} 
trabalho. Isto nos aponta a necessidade de considerarmos o princípio de estruturação do conhecimento científico no currículo. A docência, entendida como trabalho pedagógico, é, portanto, a IDENTIDADE PROFISSIONAL do professor de Educação Física e isto pode ser verificado pelos fatos, quando nos reportamos à ação profissional e identificamos seu sentido, significados, finalidades, meios e métodos ao longo da história.

Caracteriza-se, também, por ser um campo de conhecimento que se estrutura a partir das práticas históricas, socialmente produzidas, cientificamente estudadas e investigadas e criativamente ensinadas de geração a geração. Conhecimento este articulado no currículo por sistemas de complexos (PISTRAK, 2000; 2009) que ampliam as referencias do concreto no pensamento. A consolidação desta identidade para o exercício profissional requer:Sólida formação teórica de base interdisciplinar na perspectiva da formação omnilateral (MANACORDA; 1987); Unidade entre teoria/prática que significa assumir uma postura em relação à produção do conhecimento que impregna a organização curricular dos cursos, tomando o trabalho como princípio educativo, ênfase na pesquisa como meio de produção do conhecimento organizado em sistemas de complexos e práxis social como articuladora, ponto de partida e de chegada, mas em patamares mais elevados de práxis social; Gestão democrática que permita a vivência e o trabalho com relações de poder democráticas e não autoritárias; Compromisso social com ênfase na concepção sócio-histórica do trabalho, estimulando análises políticas sobre as lutas históricas pela superação da sociedade de classes, para que seja garantido o acesso aos bens a todos que dele participam em sua produção; Trabalho como princípio educativo - eixo norteador da formação omnilateral; Formação continuada para permitir a relação entre a formação inicial e continuada no mundo do trabalho; Avaliação permanente como parte integrante das atividades curriculares, de responsabilidade coletiva a ser conduzida à luz do projeto político pedagógico da instituição, abarcando as dimensões da avaliação da aprendizagem, do docente, dos programas e projetos, da instituição.

As Diretrizes aqui apresentadas foram formuladas a partir do reconhecimento de que a autonomia e a flexibilidade preconizadas pela Lei de Diretrizes e Bases da Educação Nacional (Lei no 9394/1996) são inequívocas e 
representam um ponto de apoio para a ação pedagógica. A autonomia institucional diz respeito ao preceito legal estabelecido na Constituição Nacional em seu Artigo 207, como já mencionamos nos pressupostos da presente tese.

Para garantir a unidade nacional em torno de uma consistente formação acadêmica, assumimos a idéia da base comum nacional que deverá permitir uma consistente formação teórica, interdisciplinar, a unidade teoria/prática, a gestão democrática, o compromisso social, o trabalho coletivo, a formação continuada, a avaliação permanente na formação acadêmica, para que o graduado compreenda criticamente os determinantes e as contradições do contexto em que está inserido e seja capaz de atuar na criação de condições objetivas para a transformação social. Estas idéias não são novas e vêm historicamente sendo abrigadas, desenvolvidas e defendidas no fórum da ANFOPE - Associação Nacional pela formação dos profissionais da Educação $^{12}$. A base comum nacional deverá, portanto, permitir o domínio do conhecimento e seus meios de produção em uma perspectiva de totalidade do conhecimento produzido e que permita relações e ações transformadoras na realidade, tendo no horizonte um projeto histórico de superação do modo do capital organizar a vida na sociedade - modo este criado nas relações humanas e, portanto, factível de ser alterado. A partir dessas considerações gerais, as Diretrizes Curriculares para o Curso de Graduação em Educação Física foram desenvolvidas.

DENOMINAÇÃO DO CURSO DE GRADUAÇÃO: Licenciatura Plena em Educação Física, de caráter Ampliado. Entendendo-se aqui como licenciado o que está apto a agir em diferentes campos de trabalho mediado pelo objeto de estudo, a cultura corporal.

PERFIL DO GRADUADO: O graduado em Licenciatura Plena em Educação Física com formação pautada em princípios estéticos, éticos, morais, políticos, técnicos, pedagógicos com base no rigor científico. Profissional qualificado para o exercício de atividades profissionais no campo da cultura corporal que tenham como objeto as atividades corporais e esportiva,

\footnotetext{
${ }^{12}$ Ver em: <http://anfope.spaceblog.com.br/>.
} 
entendida como um campo de estudo e ação profissional multidisciplinar, cuja finalidade é possibilitar a todos o acesso aos meios de produção da cultura corporal e ao acumulado histórico de tal produção, resultante do processo de desenvolvimento da humanidade. Meios que possibilitem a construção deste acervo compreendido como direito inalienável de todos os povos, parte importante do patrimônio histórico da humanidade e do processo de construção da individualidade humana. O egresso do curso estará apto a exercer a docência em diferentes campos de atuação profissional - educação, saúde, lazer, políticas públicas, esporte de alto rendimento -, a produzir conhecimentos científicos considerando como objeto de estudo a cultura corporal e gerenciar, administrar no sistema público e privado esta área de conhecimento e de atuação profissional relacionada à cultura corporal.

A POLÍTICA GLOBAL DE FORMAÇÃO:A política global de formação que dará identidade profissional e que é necessária, caracteriza-se historicamente pelo trabalho profissional, tem $\mathrm{o}$ ato pedagógico no trato com o conhecimento acerca da cultura corporal como identidade, abrangendo as dimensões humana e político-social e tem por finalidade a formação omnilateral ${ }^{13}$. A configuração das dimensões científicas, técnicas, pedagógicas, éticas, estéticas, morais e políticas deve ser a concepção nuclear na orientação do currículo de formação inicial do professor - profissional de Educação Física.

A formação acadêmica inicial deverá propiciar, portanto, o domínio de capacidades e habilidades para o trabalho pedagógico, o dominar dos instrumentos dos processos de construção, produção do conhecimento científico que fundamenta e orienta a ação profissional, além de competências para a gestão e administração pública e privada deste patrimônio. Além destas competências e habilidades, é imperioso que saiba mobilizar esses conhecimentos, transformando-os em ação moral, ética e política, libertadoras, emancipatórias, na perspectiva da superação da sociedade de classes.

O professor de Educação Física, além do domínio dos conhecimentos específicos para sua ação profissional deve, necessariamente, compreender e

\footnotetext{
${ }^{13}$ Omnilateral está sendo aqui empregado no sentido que lhe é atribuído na tradição marxista como sendo o contraponto à formação unilateral e que contempla as dimensões da ciência, tecnologia, humanidades, artes e educação física na perspectiva da formação para a transformação da sociedade e superação do capitalismo.
} 
enfrentar as questões envolvidas com o trabalho capitalista, seu caráter e organização. É preciso demonstrar capacidade de trabalhar de forma solidária, em grupo, com autonomia e auto-organização, para tomar decisões, bem como se responsabilizar pelas opções feitas. É preciso também que saiba avaliar criticamente sua própria atuação e o contexto em que atua e que saiba interagir cooperativamente tanto com sua comunidade profissional, quanto com a sociedade em geral.

O desenvolvimento de tais dimensões requeridas na formação do graduado em Educação Física deverá ocorrer a partir de experiências de interação teoria e prática, em que toda a sistematização teórica deve ser articulada com as situações de ação profissional balizadas por posicionamentos reflexivos com consistência e coerência conceitual.

Tais dimensões da formação humana não podem ser adquiridas apenas no plano teórico, nem no estritamente instrumental. É imprescindível, portanto, que haja coerência entre a formação oferecida, as exigências práticas esperadas do futuro profissional e a necessidade de emancipação e democratização política, humana e sociocultural para além da lógica do capital (MESZÀRÓS; 2005; 2007).

Portanto, tais dimensões da formação humana não podem ser compreendidas e nem reduzida às dimensões do aprender a aprender, do aprender a fazer, do aprender a ser e aprender a conviver, conforme a pedagogia do capital. Implicam também a consciência de classe, a formação política e a organização revolucionária (ENGELS; S/D; 1979; 1987; 1990).

O pressuposto dessas diretrizes identifica-se com uma concepção de currículo compreendido como processo de formação da competência humana histórica para a emancipação. Sendo assim, a formação é, sobretudo, a condição de refazer permanentemente as relações com a sociedade e a natureza, objetivando a superação da alienação humana.

As dimensões gerais da formação deverão ser contextualizadas e complementadas considerando as relações entre o geral da formação humana, o específico próprio à ação do professor, em particular do professor de Educação Física, definidas pela Instituição de Ensino Superior. 
Ao desenvolver o conhecimento científico em conjunto pelo coletivo incidir na formação global reconhecida nos sujeitos, nos interessa ${ }^{14}$ : a capacidade de teorização - superação dos pseudoconceitos aos conceitos científicos, das representações ao real concreto, da alienação à desalienação; a organização do trabalho pedagógico - na prática pedagógica, no trato com o conhecimento, nos objetivos - avaliação; o sistema axiológico - atitudes, valores, representações perante a realidade complexa e contraditória; a compreensão e utilização dos processos de produção do conhecimento científico e no acesso coletivo dos produtos das relações de produção do conhecimento alterando-se significativamente a organização do trabalho; a compreensão política das relações de poder e da força que adquire 0 conhecimento em dadas relações de produção - força produtiva, ideológica e política.

Sucintamente, resumimos a proposta superadora e apresentamos um quadro comparativo que nos permite reconhecer nas variáveis os aspectos avançados que estamos propondo.

Com esta base explicativa estamos apresentando, portanto, a minuta que se segue.

\section{CONSELHO NACIONAL DE EDUCAÇÃOMINUTA DE RESOLUÇÃO}

\section{Institui as Diretrizes Curriculares Nacionais do Curso de Graduação:Licenciatura Plena de Caráter Ampliado em Educação Física.}

O Presidente da Câmara de Educação Superior do Conselho Nacional de Educação, tendo em vista o disposto no Art. $9^{\circ}$, do $\S 2^{\circ}$, alínea "C", da Lei 9.131, de 25 de novembro de 1995, e com fundamento no Parecer CNE/CES ___ de _ _ de ___ de 2011, peça indispensável do conjunto das presentes Diretrizes Curriculares Nacionais, homologado pelo Senhor Ministro da Educação em de de 2011.

\footnotetext{
${ }^{14}$ Terminologia provisória para designar o reconhecido e amplo campo do qual decorrem saberes, conhecimentos e práticas consideradas e institucionalizadas com diferentes fins, metas, objetivos e interesses de classe. Caracterizase básica e essencialmente pelo ato pedagógico que utiliza nas relações de produção as atividades corporais sistematizadas. Exemplificando: Nas escolas tem-se privilegiado conteúdos como Jogos, Esportes, Dança, Ginástica e outros, de acordo com interesses de classe predominantes, hegemônicos. Tal predominância pode ser identificada em cada local de atuação e intervenção profissional.
} 


\section{RESOLVE:}

Art. 1- -A presente Resolução institui as Diretrizes Curriculares Nacionais do Curso de Graduação: Licenciatura Plena de Caráter Ampliado em Educação Física, a serem observadas na organização curricular das Instituições do Sistema de Educação Superior do País.

Art. 20 -As Diretrizes Curriculares Nacionais do Curso de Graduação:Licenciatura Plena de Caráter Ampliado em Educação Física definem os princípios, fundamentos, condições e procedimentos da formação de professores, profissionais de Educação Física, estabelecidas pela Câmara de Educação Superior do Conselho Nacional de Educação, para aplicação em âmbito nacional na organização, desenvolvimento e avaliação dos projetos pedagógicos dos Cursos de Licenciatura Plena de Caráter Ampliado em Educação Física das Instituições do Sistema de Ensino Superior.

Art. 3o - A Educação Física é um campoacadêmico-profissional que se fundamenta em conhecimentos das ciências humanas, sociais, da saúde, exatas e da terra, da arte e da filosofia. Portanto, sua matriz científica é a história, do homem e sua relação com a natureza, com os demais seres humanos e consigo mesmo.

Art. 4 - O Curso de Licenciatura Plena de Caráter Ampliado em Educação Física deverá assegurar uma formação generalista, humanista e crítica, qualificadora da intervenção acadêmico-profissional, fundamentada no rigor científico e na reflexão filosófico tendo o trabalho como principio educativo.

Parágrafo Único - O graduado em Educação Física deverá estar qualificado para conhecer, compreender e analisar criticamente a realidade social para nela intervir por meio das diferentes manifestações e expressões da cultura corporal.

Art. 5o - A estrutura curricular do Curso de Graduação: Licenciatura Plena de Caráter Ampliado em Educação Física deverá pautar-se em uma política global de formação, que eleve as funções psíquicas superiores, a capacidade do pensamento teórico e que observe os seguintes princípios:

1) trabalho pedagógico como base da identidade do professor, profissional de Educação Física;

2) compromisso social da formação na perspectiva da omnilateralidade;

3) sólida e consistente formação teórica, formação política; 
4) elevação da consciência de classe;

5) articulação entre ensino, pesquisa e extensão;

6) indissociabilidade teoria-prática;

7) tratamento coletivo e interdisciplinar do conhecimento;

8) ação investigativa crítica, solidária, coletiva, interdisciplinar na produção do conhecimento científico;

9) articulação entre conhecimentos de formação ampliada, formação específica e aprofundamento a partir de sistemas de complexos que assegurem a compreensão radical, de totalidade e de conjunto;

10) avaliação permanente;

11)formação continuada;

12)respeito à autonomia institucional;

13)gestão democrática;

14)condições objetivas de trabalho;

15)autodeterminação dos estudantes.

Art. 6o - A identidade profissional baseada no trabalho pedagógico e as competências no sentido amplo de formação humana omnilateral de natureza político-social, ético-moral, científico-pedagógica e técnico-profissional, deverão constituir a concepção nuclear do currículo de formação do professor, profissional de Educação Física.

Art. 7 -O currículo para o Curso de Graduação: Licenciatura Plena de Caráter Ampliado em Educação Física será constituído por Conhecimentos de Formação Ampliada Geral; Conhecimentos Identificadores da área da Educação Física; Conhecimentos do Aprofundamento da Práxis Pedagógica e Conhecimentos das Teorias de Conhecimento e do desenvolvimento da pesquisa científica e atitudes científicas. Cinquenta por cento (50\%) destes conhecimentos serão organizados em disciplinas e atividades de caráter obrigatório e cinquenta por cento $(50 \%)$ de caráter opcional.

Parágrafo $1^{\circ}$ - Os Conhecimentos de Formação Ampliada advêm das áreas das ciências sociais, humanas, da terra, da saúde, ciências exatas e da natureza e abrangem as seguintes dimensões:

a) Relação ser humano - Modo de Produção;

b) Relação ser humano - Trabalho - Modo de Vida;

c) Relação ser humano - Sociedade - Poder; 
d) Relação ser humano - Educação, Saúde e Lazer - Cultura.

Parágrafo 20 - Os Conhecimentos Identificadores da Educação Física abrangem as seguintes dimensões:

a) Cultura corporal - natureza humana e meio ambiente

b) Cultura Corporal - mundo do trabalho/campos de trabalho;

c) Cultura corporal - Territorialidade e Cultura;

d) Cultura corporal - Política Cultural (Educação, saúde, lazer, treino de alto rendimento).

Parágrafo 3 - Os Conhecimentos do Campo de Aprofundamento Práxis Pedagógica da Educação Física são compreendidos como o conjunto de fundamentos específicos que tratam de singularidades e particularidades na elaboração, implantação, implementação e avaliação das ações acadêmico-profissionais, em sistemas de complexos, em diferentes campos de atuação profissional;

I - Cada Instituição de Ensino Superior deverá propor seus sistemas de complexos, definindo a articulação de conhecimentos e experiências que os caracterizarão de acordo com sua capacidade investigativa e de pesquisa em diferentes campos de atuação profissional.

Art. 8 - O tempo de integralização do Curso de Graduação: Licenciatura Plena de Caráter Ampliado em Educação Física será definido pelas Instituições de Ensino Superior, respeitando o mínimo de duração e de carga horária de 4 anos e de 2.800 horas, respectivamente.

Parágrafo Único - Da carga horária total, 30\% (trinta por cento) será destinada ao Conhecimento de Formação Ampliada, 50\% aos Conhecimentos Identificadores da Educação Física e $20 \%$ aos Conhecimentos Identificadores de Aprofundamento da Educação Física, admitindo-se uma variação de até $5 \%$ para mais ou para menos.

Art. 9 - A Prática de Ensino com 400 horas deverá ser desenvolvida desde o início do curso, tendo como objeto de estudo a docência, devendo o Estágio Curricular obrigatório, com 400 horas, a partir do cumprimento de $50 \%$ da carga horária total para integralizar o currículo, sendo, necessariamente, supervisionado pela instituição formadora e articulado a projetos de ensino- 
pesquisa-extensão, tendo como objeto a atuação docente em diferentes campos de atuação profissional.

Parágrafo 1- Da carga horária total do Estágio Curricular, 60\% deverá ser cumprida tratando de diferentes sistemas de complexos, em diferentes campos de trabalho da Educação Física - saúde, lazer, alto rendimento ao longo do curso e, $40 \%$ no campo de trabalho vinculado ao sistema formal de ensino - Educação Infantil, Ensino Fundamental, Médio, Superior e Educação de Jovens e Adultos.

Art. 10 - Para os Cursos Graduação: Licenciatura Plena de Caráter Ampliado em Educação Física será exigida a iniciação científica orientada por professores pesquisadores, mestres e doutores, articulados a grupos e linhas de pesquisa, devendo culminar com a elaboração de um trabalho científico de conclusão de curso (TCCC), que caracterize uma monografia de base, articulados aos programas de iniciação científica e de incentivo à docência, na forma definida pela própria Instituição de Ensino Superior.

Art. 11 - As atividades complementares deverão perfazer 200 horas e serem incrementadas ao longo do curso, devendo ser entendidas como conhecimentos adquiridos de forma autônoma pelo graduando por meio de estudos e de práticas independentes, presenciais e/ou à distância, sob a forma de estágios extracurriculares, programas de extensão, congressos, seminários e cursos, atividades estas a serem reconhecidas pela Instituição de Ensino Superior.

Art. 12 - Na organização do Curso de Graduação: Licenciatura Plena de Caráter Ampliado em Educação Física deverá ser indicada a modalidade: seriada anual, seriada semestral, sistema de créditos ou modular.

Art. 13 -O Curso de Graduação: Licenciatura Plena de Caráter Ampliado em Educação Física deverá obedecer à legislação específica emanada do Conselho Nacional de Educação para a Formação de Professores da Educação Básica e ser ampliada para atuação profissional tendo a docência como elemento identificador da atuação em diferentes campos de atuação do profissional: professor de Educação Física.

Art. 14 - A implantação e o desenvolvimento do projeto pedagógico do Curso de Graduação: Licenciatura Plena de Caráter Ampliado em Educação Física 
deverá ser acompanhado e permanentemente avaliado, a fim de permitir os ajustes que se fizerem necessários à sua contextualização e aperfeiçoamento.

Parágrafo $1^{0}$ - A avaliação dos graduandos deverá basear-se nos princípios norteadores que assegurem uma consistente base teórica e o desenvolvimento de competências no sentido amplo de formação humana de natureza político-social, ético-moral, científico-pedagógica e técnicoprofissional.

Parágrafo $2^{\circ}-$ As metodologias e critérios empregados para acompanhamento e avaliação do processo ensino-aprendizagem e do próprio projeto pedagógico do curso deverão estar em consonância com 0 sistema de avaliação e o contexto curricular adotados pela Instituição de Ensino Superior.

Art. 15 - Perfil do Egresso: O professor, profissional de Educação Física, formado pelo Curso de Graduação: Licenciatura Plena de Caráter Ampliado em Educação Física, tendo integralizado o currículo, estará apto a desenvolver as funções nos seguintes campos de trabalho e atuação profissional: a) Docência na Educação Infantil, Ensino Fundamental e Médio, Educação Superior, Educação de Jovens e Adultos; b) Gestão e Administração Esportiva que integre as diversas atuações e funções do trabalho pedagógico e dos processos educativos e de treino corporal, especialmente no que se refere ao planejamento, à administração, à coordenação, ao acompanhamento, à supervisão, à inspeção, à orientação e à avaliação em contextos escolares e não escolares no trato com o objeto de estudo - cultura corporal; c) Produção e difusão do conhecimento científico sobre a cultura corporal e do campo de trabalho da Educação Física, Esporte e Lazer e da Ciência do Esporte.

Art. 16 - Esta Resolução entra em vigor na data de sua publicação, revogadas as disposições em contrário.

Brasília, DF, de de $20 \ldots$ Presidente da CNE/CES

\section{A GUISA DE CONCLUSÃO}

Retomando a categoria "possibilidade de essência" descrita por Cheptulin (1982, p. 342) como sendo aquela cuja realização está ligada à 
modificação da essência da coisa, com a sua transformação em uma outra coisa, compreendemos que determinadas condições objetivas estão colocadas para avançarmos na luta contra a divisão na formação do professor - profissional de Educação Física.

Sintonizados com a luta de resistência, travada neste momento histórico, em todo o planeta, contra o imperialismo, contra os ajustes, contra o modo de vida capitalista, contra a perda de direitos e conquistas, consideramos de grande importância reconhecer que a possibilidade está posta (TROTSKY, 2008; 2007). Este reconhecimento nos permitirá orientar a atividade prática e, em particular, a realização de planificações concretas de curto, médio e longo prazo.

As possibilidades estão em relação direta com a atividade prática humana e sua consideração assegura uma orientação adequada das vias e dos meios de se chegar a esse ou àquele resultado prático. As possibilidades são ilimitadas, à medida que a matéria passa de um estado qualitativo a outro e aparecem novas possibilidades.

Temos possibilidade, sim, de alterar os rumos da história (MARX, 1980; $1983 ; 1984 ; 1990)$ e de romper os nós que foram amarrados pela construção de consensos que estão sendo desfeitos pela luta de classes .

O exemplo desta luta está expresso no Manifesto "Educação Física é uma só! Formação Unificada Já" da executiva Nacional dos Estudantes de Educação Física que, na Gestão 2010/2011, apresenta 10 "motivos para sermos a favor da Licenciatura Ampliada", conforme ressaltamos no decorrer do presente texto. Nos periódicos científicos, como vimos em relação à Revista Motrivivência que, em seus exemplares denominados Educação Física e o Mundo do Trabalho I (Ano XXII, n. 35, jun. 2010) e Educação Física e o Mundo do Trabalho II (Ano XXIII, n. 36, jun. 2011), tratam da temática da Educação Física e o mundo do trabalho. Está expressa também no MNCR e seus embates jurídicos e em Audiências Públicas, marcadas pelo Ministério Público, perante o qual as verdadeiras intencionalidades do CONFEF/CREF se manifestam. E, por fim, nos estudos de Taffarel (1993), Almeida (2002), Nozaki (2004), Alves (2005), Santos Júnior (2005), Lemos (2008), Brito Neto (2009), Cruz (2009), Coimbra, (2010), Silva e Frizzo (2011), Dias (2011), Aranha (2011) Dutra (2011), Morschbacher (2012) que demonstram os embates no plano cientifico, 
da produção do conhecimento, na formação de professores, na atuação em campos de trabalho.

As propostas de unificação são minoritárias, mas estão sendo levadas em cursos que discutem a reformulação e a possibilidade de Unificação como são exemplos, os debates e as propostas na UFSM, UFRGS, UFG, UFBA, UEPA, UFMS, UNIMAT, entre outros. O processo está em curso e não pode ser dado como acabado. Necessita, sim, a precisão nos rumos, nas tendências para que se dê, com precisão, o combate ao reacionarismo que somente beneficia 0 capital, tanto na formação inicial e continuada do profissional: Professor de Educação Física, quanto na atuação em campos de trabalho. Neste sentido, estamos nos aliando às posições de resistência e de ofensiva e defendendo a tese da necessidade da formação unificada em um único curso de Graduação: Licenciatura Plena de Caráter Ampliado que deverá ser complementado com cursos de especialização, mestrado e doutorado que aprofundarão a consistente base teórica, a consciência de classe, a formação política e a autodeterminação revolucionária dos professores de Educação Física formados nas universidades, com autonomia didático-científica, administrativa e de gestão financeira e patrimonial e no princípio da indissociabilidade entre ensino, pesquisa e extensão.

\section{REFERÊNCIAS BLIOGRÁFICAS}

ALMEIDA, Renan de (org.). Os bastidores da regulamentação do profissional de Educação Física. Vitória: CEFD/UFES, 2002.

ARANHA, Otávio Luiz Pinheiro. Currículo de Formação de professores de Educação Física no Estado do Pará: conteúdos curriculares, concepções pedagógicas e modelos de profissionalidade. 2011. 270f. Dissertação (Mestrado em Educação)-Instituto de Ciências da Educação, Universidade Federal do Pará, Belém, 2011.

A VERDADE. Revista Teórica da Quarta Internacional. São Paulo, n. 62/63, jan. 2009. 
BRASIL. Constituição da República Federativa do Brasil de 1988, de 05 de outubro de 1988. Brasília, 2009. Disponível em: $<$ http://www.planalto.gov.br/ccivil 03/constituicao/constitui\%C3\%A7ao.htm>. Acesso em: 25 set. 2011.

BRASIL, Conselho Nacional de Educação. Resolução CNE/CP 01/2002, de 18 de fevereiro de 2002. Institui as diretrizes nacionais de formação de professores para a educação básica. Brasília, 2002a.

. Conselho Nacional de Educação. Resolução CNE/CP 02/2002, de 19 de fevereiro de 2002. Instituição da duração e carga horária dos cursos de licenciatura. Brasília, 2002b.

. Conselho Nacional de Educação. Câmara de Educação Superior. Parecer CNE/CES 058/2004, de 18 de fevereiro de 2004. Institui as Diretrizes Curriculares Nacionais para os cursos de graduação em Educação Física, em nível superior de graduação plena. Brasília, 2004a.

. Conselho Nacional de Educação. Câmara de Educação Superior. Resolução CNE/CES 07/2004, de 31 de março de 2004. Institui as Diretrizes Curriculares Nacionais para os cursos de graduação em Educação Física, em nível superior de graduação plena. Brasília, 2004b.

BRITO NETO, Aníbal Correia. O Impacto das diretrizes Curriculares Nacionais nos projetos Político pedagógico dos Cursos de Graduação em Educação Física do estado do para. 2009. 129 f. Dissertação (Mestrado em Educação). Universidade Estadual do ará, Centro de Ciências Sociais e Educação. Programa de Pós-Graduação em Educação, Belém, 2009.

BRZEZINSKI, Iria. Dilemas e desafios nas políticas de formação de professores e de valorização dos profissionais da educação. ANPED, 05.10.2009. Disponível em: $<$ http://www.anpae.org.br/congressos antigos/simposio2009/135.pdf $>$. Acesso em: 25 mai. 2012. 
BRZEZINSKI, Iria. Anfope em Movimento: 2008-2010. Brasília: Líber Livro. Anfope: Capes, 2011.136 p.

CASTIONI, Remi. O Sistema de Proteção ao Trabalho no Brasil. Campinas: Autores Associados, 2008.

CHEPTULIN, Alexandre. A dialética materialista: categorias e leis da dialética. São Paulo: Alfa-Omega, 1982.

COIMBRA, Tatiane Carneiro. O reordenamento do trabalho do professor de Educação Física e a organização empresarial do âmbito do Fitness: CONFEF/CREF, ACAD e SINDCAD. Motrivivência, Florianópolis, ano XXII, n. 35, p. 62-78, dez. 2010.

CONFEF. Estatuto do Conselho Federal de Educação Física. Rio de Janeiro, nov. 2010a. Disponível em: $<$ http://www.confef.org.br/extra/conteudo/default.asp?id=471>. Acesso em: 25 set. 2011.

CONFEF. Licenciatura e/ou Bacharelado: opções de graduação para intervenção profissional. Revista da Educação Física, Rio de Janeiro, ano VI, n. 19, mar. 2006.

CONFEF. Carga horária o curso de bacharelado em Educação Física. Revista da Educação Física, Rio de Janeiro, ano IX, n. 32, jun. 2009.

CONFEF. O Sistema CONFEF/CREFs informa. Revista da Educação Física, Rio de Janeiro, ano IX, n. 38, dez. 2010b.

CRUZ, Amália Catharina Santos. O embate de projetos na formação de professores de Educação Física: além da dualidade Licenciatura-Bacharelado. 2009. 151f. Dissertação (Mestrado em Educação)-Centro de Ciências da Educação, Universidade Federal de Santa Catarina, Florianópolis, 2009. 
DIAS, Fernanda Braga Magalhães. A fragmentação da formação de professores de educação física: minimização da formação sob a ordem do capital. 2011. 293f. Dissertação (Mestrado em Educação)-Centro de Ciências da Educação, Universidade Federal de Santa Catarina, Florianópolis, 2011.

DIAS JÚNIOR; Elson Moura;LIMA; Thiago Firminio de. MNCR: 10 anos de luta pela regulamentação do trabalho. Feira de Santana: UEFS Editora, 2010.

DUARTE, Newton. A individualidade para-si: contribuição a uma teoria histórico-social da formação do indivíduo. Campinas: Autores Associados, 1993.

. Concepções afirmativas e negativas sobre $o$ ato de ensinar. Cadernos CEDES, Campinas, v. 19, n. 44, p. 85-106, abr. 1998.

. Vigotski e o "Aprender a Aprender": crítica às apropriações neoliberais e pós-modernas da teoria vigotskiana. Campinas: Autores Associados, 2000.

- Sociedade do Conhecimento ou Sociedade das Ilusões? Quatro Ensaios Crítico-Dialéticos em Filosofia da Educação. 1.ed. Campinas: Autores Associados, 2003. $110 \mathrm{p}$.

DUTRA, Geovanna Caroline Zanini. Atualidade do debate sobre a formação unificada na Educação Física: um balanço da correlação de forças na área. 2011. Monografia (Especialização em Metodologia do Ensino e da Pesquisa em Educação Física, Esporte e Lazer)-Faculdade de Educação, Universidade Federal da Bahia, Salvador, 2011.

ENGELS, Friedrich. A dialética da natureza. Rio de Janeiro: Paz e Terra, 1979.

A origem da família, da propriedade privada e do Estado. Rio de Janeiro: Civilização Brasileira, 1987. 
. O papel do trabalho na transformação do macaco em homem. São Paulo: Global, 1990.

. Do socialismo utópico ao socialismo científico. São Paulo. Moraes. S/D.

FREITAS, Luiz Carlos. Projeto histórico, ciência pedagógica e "didática". Educação \& Sociedade, São Paulo, ano IX, v. 09, n. 27, p.122-140, set. 1987. MANACORDA, Mario Alighiero. História da educação: da antiguidade aos nossos dias. São Paulo: Autores Associados, 1989.

MORAES, Maria Celia Marcondes de. O iluminismo às avessas: produção do conhecimento e políticas de formação docente. Rio de Janeiro: Lamparina Editora, 2003.

LEMOS,Lovane Maria. Formação profissional e a inserção de egressos do Curso de Educação Física da UNIJUI no mercado e no mundo do trabalho: 1995-2006. Trabalho de Conclusão de Curso(Licenciatura em Educação Física)-Universidade Regional do Noroeste do Estado do Rio Grande do Sul, ljuí, 2008.

MORSCHBACHER, Márcia. Reformas Curriculares e a formação do (novo) trabalhador em Educação Física: a subsunção da formação à lógica privada/mercantil. 2012. 247f. Dissertação (Mestrado em Educação Física)Escola Superior de Educação Física, Universidade Federal de Pelotas, Pelotas, 2012.

MOTRIVIVÊNCIA. Educação Física e o Mundo do Trabalho I. Florianópolis, ano XXII, n. 35, jun. 2010.

MOTRIVIVÊNCIA. Educação Física e o Mundo do Trabalho II. Florianópolis, ano XXIII, n. 36, jun. 2011. 
MARX, Karl. Contribuição à crítica da economia política. 2.ed. São Paulo: Martins Fontes, 1983.

. O Capital. Rio de Janeiro: Civilização Brasileira, 1980.

O 18 Brumário de Luís Bonaparte. São Paulo: Edições Mandacaru, 1990.

MARX, Karl; ENGELS, Friedrich. A ideologia Alemã. São Paulo: Martin Claret, 2005.

. Manifesto do partido comunista. São Paulo: Global, 1984.

MARX, Karl; ENGELS, Friedrich; TROTSKY, Leon. O programa da revolução. Brasília: Nova Palavra, 2008.

MAZO, Janice Zarpellon. História do Centro de Educação Física e Desportos/UFSM 25 anos.Santa Maria/RS UFSM/CEFD, 1997.

MÉSZÁROS, István. A educação para além do capital. São Paulo: Boitempo, 2005.

MÉSZÁROS, István. O desafio e o fardo do tempo histórico. São Paulo: Boitempo, 2007.

MORAES, Maria Célia Marcondes de. Dupla problemática do objeto da história: ontológica e metodológica. In: . Reformas de ensino, modernização administrada: a experiência de Francisco Campo - anos vinte e trinta. Florianópolis: UFSC/CED/Núcleo de Publicações, 2000.

NEVES, Lucia Maria. Brasil ano 2000: uma nova divisão de trabalho na educação. Rio de Janeiro: Papéis e Cópias, 1997.

. Educação: um caminhar para o mesmo lugar. In: LESBAUPIN, Ivo 
(org.). O desmonte da nação: Balanço do governo FHC. Petrópolis: Vozes, 1999.

. (org.). Educação e política no limiar do século XXI. Campinas: Autores Associados, 2000.

. (org.). O empresariamento da educação: novos contornos do ensino superior no Brasil dos anos 1990. São Paulo: Xamã, 2002.

. (org.). Reforma universitária do governo Lula: reflexões para o debate. São Paulo: Xamã, 2004.

- (org.). A nova pedagogia da hegemonia: estratégias do capital para educar o consenso. São Paulo: Xamã, 2005. 311p.

NASCIMENTO, Maria; SAVIANI, Dermeval; LOMBARDI, José. A escola pública no Brasil: História e Historiografia. Campinas: Autores Associados, 2005.

NOZAKI, HajimeTakeuchi. Educação Física e reordenamento no mundo do trabalho: mediações da regulamentação da profissão. 2004. 383f. Tese (Doutorado em Educação)-Faculdade de Educação, Universidade Federal Fluminense, Rio de Janeiro, 2004.

OLIVEIRA, Francisco de. Crítica à razão dualista: o ornitorrinco. São Paulo: Boitempo Editorial, 2003.

PETRAS, James. Os intelectuais em retirada. In: COGGIOLA, Osvaldo (org.) Marxismo hoje. São Paulo: Xamã, 1996. p.16-20.

QUELHAS, Álvaro; NOZAKI, HajimeTakeuchi. A Formação do professor de Educação Física e as novas diretrizes curriculares frente aos avanços do capital. Motrivivência, Florianópolis, ano XVIII, n. 26, p. 69-87, Jun. 2006.

PISTRAK, MoiseyMikhaylovich. Fundamentos da escola do trabalho. São Paulo: Expressão Popular, 2000. 
A Escola Comuna. São Paulo: Expressão

Popular. 2009.

RICOEUR, Paul. Interpretação e ideologia. Rio de Janeiro: Francisco Alves, 1988.

SANTOS JÚNIOR, Claudio de Lira. A formação de professores de Educação Física: A mediação dos parâmetros teóricos metodológicos. 2005. 157 f. Tese (Doutorado em Educação)-Faculdade de Educação, Universidade Federal da Bahia, Salvador, 2005.

SAVIANI, Dermeval (org.). Instituições escolares no Brasil: conceito ereconstrução histórica. Campinas: Autores Associados, 2007.

SAVIANI, Dermeval. ALMEIDA, Jane Soares de; SOUZA, Rosa Fátima de; VALDEMARIN Vera. O Legado educacional do século XX no Brasil. Campinas: Autores Associados 2006a.

SAVIANI, Dermeval. ALMEIDA, Jane Soares de; SOUZA, Rosa Fátima de; VALDEMARIN Vera. O Legado educacional do séculoXIX no Brasil. Campinas: Autores Associados, 2006.

SILVA, Guilherme Gil; FRIZZO, Giovani. Crítica à regulamentação da profissão e à produção científica defensora do sistema CONFEF/CREFs. Motrivivência, Florianópolis, ano XXIII, n. 36, p. 149-168, jun. 2011.

TAFFAREL, Celi. A formação do profissional de Educação Física: O processo de trabalho pedagógico e o trato com o conhecimento no Curso de Licenciatura da UNICAMP. 1993. 301f. Tese (Doutorado em Educação)-Faculdade de Educação, Universidade Estadual de Campinas, Campinas, 1993. 
TAFFAREL, Celi N. Zülke. Do trabalho em geral ao trabalho pedagógico: contribuições ao debate sobre trabalho pedagógico na Educação Física. Motrivivência, Florianópolis, ano XXII, n. 35, p. 18-40, dez. 2010.

TAFFAREL, Celi N. Zülke; SANTOS JÚNIOR, Cláudio de Lira. Formação humana e formação de professores de educação física: para além da falsa dicotomia licenciatura $X$ bacharelado. In: TERRA, D. V. e SOUZA JÚNIOR, M. (org.) Formação em educação física \& ciências do esporte: políticas e cotidiano. São Paulo: Aderaldo \&Rothschild: Goiânia, GO: CBCE, 2010. p. 1348.

TROTSKY, Leon. Programa de transição. In: MARX, Karl; ENGELS, Friedrich; TROTSKY, Leon. O programa da revolução. Brasília: Nova Palavra, 2008.

A revolução permanente. São Paulo: Expressão Popular, 2007.

VIGOTSKY, Lev. A formação social da mente. São Paulo: Martins Fontes, 1987.

. Pensamento e linguagem. São Paulo: Martins Fontes, 1988.

VIGOTSKY, Lev; LEONTIEV, Alexei; LURIA, Alexander. Linguagem, desenvolvimento e aprendizagem. São Paulo: Ícone, 1988. 
TEACHEROF PHYSICAL EDUCATION:GUIDELINES FOREDUCATIONUNIFIED.

\begin{abstract}
The text describes the development of physical education teachers. Criticizes the current curriculum guidelines, the division in the formation and action of the Federal System of Physical Education / Physical Education Regional Councils (CONFEF / CREF).Explains the historical roots that determine this situation, recognizing trends. It presents a scientific rationale that supports the proposition of curriculum guidelines for a full degree course, expanded character, in contrast to current guidelines proposed by the National Education Council (CNE) and the System CONFEF

CREF.
\end{abstract}

Keywords:Teacher of PhysicalEducationcurriculumguidelines.

PROFESOR DE EDUCACION FISICA: DIRECTRICES PARA LA EDUCACION UNIFICADO.

\title{
RESUMEN
}

El texto describeel desarrollo de losprofesores de educación física. Critica alas directricesdel plan de estudiosactuales, la división en la formacióny la acción delSistema Federal deEducación Física/ConsejosRegionalesde Educación Física(CONFEF /CREF). Explicalas raíces históricasque determinanesta situación,el reconocimiento delas tendencias. Se presenta unajustificación científicaque apoyala propuesta delineamientos curricularespara un cursoen toda su magnitud, el carácter ampliado, en contraste con las actuales directricespropuestas por elConsejo Nacional de Educación(CNE)y el Sistema deCONFEF/CREF.

Palabras Clave: Profesor de EducaciónFísicadirectricesdel plan de estudios.

Endereço para correspondencia: taffarel@ufba.br 